\title{
PACTO SOCIAL E GARANTIA DE AUTOPRESERVAÇÃO EM THOMAS HOBBES
}

\section{ADELMO JOSÉ DA SILVA ${ }^{1}$}

RESUMO: O presente estudo possui como objetivo explicitar e refletir, à luz do pensamento de Thomas Hobbes, a forma natural de vida e da ação dos indivíduos que desencadearia a predominância do estado de guerra e de completa insegurança. Frente a este estado de natureza, a alternativa, com vistas ao estabelecimento da paz e da segurança, seria a introdução de um governo absoluto, mediante um pacto social, em condições de assegurar o estado de direito. $\mathrm{O}$ estabelecimento desta forma de governo, em contrapartida, implicaria no sacrifício da liberdade absoluta, visto que, para este pensador, somente o estado forte, centralizador de todos os poderes e identificado com o Leviatã poderia assegurar a segurança prevista no contrato social. Ao discorrer sobre o tema, objetivamos, outrossim, conduzir a uma reflexão sobre eventuais consequências políticas decorrentes deste entendimento contratualista.

PALAVRAS-CHAVE: Pacto social; Autopreservação; Indivíduo; Sociedade; Filosofia.

ABSTRACT: The present study aims to explain and reflect, in the light of Thomas Hobbes' thinking, the natural way of life and the action of individuals that would trigger the predominance of the state of war and complete insecurity. Faced with this state of nature, the alternative, with a view to establishing peace and security, would be the introduction of an absolute government, through a social pact, in conditions to ensure the rule of law. The establishment of this form of government, on the other hand, would imply the sacrifice of absolute freedom, since, for this thinker, only the strong state, centralizing all powers and identified with the Leviathan could ensure the security provided for in the social contract. When discussing the theme, we also aim to lead to a reflection on possible political consequences arising from this contractual understanding.

KEYWORDS: Social Pact; Self-preservation; Individual; Society; Philosophy.

Inicialmente, consideramos que Thomas Hobbes teorizou acerca do estado de natureza, onde o exercício da liberdade absoluta, levada aos seus extremos, inviabilizaria a vida social, por desencadear um clima de insegurança generalizada. O pacto social, alternativa encontrada, tendo em vista a solução da inviabilidade da convivência social no estado anteriormente apontado, exigiria por parte dos indivíduos o abrir mão da liberdade absoluta e a delegação de

\footnotetext{
${ }^{1}$ Professor Titular do Departamento de Filosofia e Métodos da Universidade Federal de São João del-Rei (UFSJ). Doutor em Filosofia Política pela Universidade Gama Filho (UGF). E-mail: adelmojs@ufsj.edu.br.
} 
poderes absolutos ao Estado. Este, de posse de tais poderes a ele delegados pelos pactuantes, por sua vez, asseguraria a todos as condições indispensáveis para uma vida social pautada na segurança.

Desse modo, o estado natural seria substituído pelo estado de direito, então contando com normas de convivência, indispensáveis à vida social, cujas feições teriam identificações absolutistas e leviatânicas.

Consideramos também que o contexto histórico de Thomas Hobbes é marcado por contradições de ordem religiosa, especialmente em função da ortodoxia e da consequente dificuldade de tolerar o outro, como aquele que possui direito de manifestação e expressão nesta área. Aliado a este fato, há também as dificuldades de convivência política em função da falta de liberdade para o indivíduo poder se expressar, pensar e agir politicamente.

Embora havendo todas estas dificuldades, Hobbes não se omitiu e, tampouco, deixouse levar por elas. Pelo contrário, ainda que houvesse, o autor do Leviatã procurou se manifestar, expondo suas reflexões e instigando seus ouvinte e leitores a pensar sobre problemas, notadamente os de ordem política. Suas ideias neste campo se fazem compreender, sobretudo, quando associadas ao nominalismo e ao materialismo. Isto porque um dos traços marcantes de suas reflexões é a coerência em termos de discurso e conteúdo programático. De tal forma que isolar sua reflexão política, desvinculando-a de sua noção de materialismo e de nominalismo, poderia comprometer uma compreensão mais abrangente de suas ideias.

A ação humana ocupa lugar de destaque quando a reflexão política é apresentada por este filósofo. Numa relação bastante estreita com a ação humana, Hobbes refere-se às ações moral e política. É o que leva este pensador a trabalhar uma categoria de grande importância, por ele denominada de "conatus" que pode ser traduzida, para efeito de compreensão, em empenho ou também em esforço. Ele inicia a explicitação afirmando que há um movimento interno ao homem e que este tem o seu desencadeamento a partir da percepção de que há algo que agrada e, em contrapartida, algo que desagrada. Eis suas palavras:

Este esforço, quando vai em direção de algo que o causa, chama-se apetite ou desejo, sendo o segundo o nome mais geral, e o primeiro frequentemente limitado a significar o desejo de alimento, nomeadamente a fome e a sede. Quando o esforço vai no sentido de evitar alguma coisa, chama-se igualmente aversão. As palavras apetite e aversão vêm do latim, e ambas designam movimentos, um de aproximação e outro de afastamento. Também os gregos tinham palavras para exprimir o mesmo, hormé e aphormé. A própria natureza impõe aos homens certas verdades, com as quais depois eles vão se chocar quando procuram alguma coisa fora da natureza. Pois as escolas não encontram no simples apetite de mover-se qualquer espécie de movimento, chamam-lhe movimento metafórico; o que não passa de uma definição absurda, porque as palavras podem ser chamadas metafóricas, não os corpos e os movimentos (HOBBES, 1988, 32). 
Assim sendo, o movimento que acontece sempre a partir desta percepção inicial, se desenvolve sempre no sentido de aproximar-se daquilo que provoca prazer, satisfação e alegria, e afastando-se do que é oposto a este sentimento, a saber, do que desagrada e traz desconforto e sofrimento. A ação humana é vista, então, a partir de uma ótica determinista, segundo este pensador, o que pode ser demonstrado como a própria percepção visual. A partir desta percepção, o olho volta-se para aquilo que provoca prazer, satisfação e alegria e afasta-se daquilo que não produz as supracitadas experiências.

Desse modo, podemos observar que Hobbes coloca a experiência histórica como sendo um campo altamente competitivo. Uma vez que a alegria é proporcionada pela posse do que causa prazer e a tristeza e o sofrimento são provocados pelo que acarreta o desprazer. E, nesta realidade histórica, o homem, naturalmente vai desejar aproximar-se sempre mais daquilo que lhe provoca prazer. E, assim, não apenas o homem, na sua individualidade e solidão ontológica, mas todos os homens, numa corrida desenfreada e altamente competitiva, a partir da percepção de que os objetos desta busca são comuns a todas as ambições e desejos. Certo de que, quando mais de um desejo se volta para o mesmo objeto, o conflito é inevitável, sobressaindo-se, historicamente, aquele que possui um maior poder capaz de atingir o seu objetivo. A vida humana não merece outra interpretação senão a de ser um campo destinado a esta luta incessante.

Perguntamo-nos, qual a relação entre o pacto social e a autopreservação?

Thomas Hobbes considera, teoricamente, a inerência de um instinto marcadamente egoísta na natureza humana. Visando exclusivamente os seus interesses, os indivíduos são capazes das maiores perversidades quando estão em jogo os seus egoísticos objetivos. Este fato ocorre de forma generalizada, onde todos representam ameaça a todos. E, dentro desta realidade teorizada por esse pensador inglês, o comprometimento da segurança pessoal é uma realidade que requer busca de solução, sob pena de não ser possível a vida em sociedade. A garantia de autopreservação torna-se uma necessidade absoluta.

O pacto social surge como o mecanismo essencial apontado por Hobbes, capaz de fazer esta passagem do estado natural para o estado de direito, assegurando, assim, a autopreservação vista como necessidade indispensável no convívio social.

A história humana é, portanto, comparável a esta corrida, na qual a busca do prazer é uma constante e partilhada por todos os homens. De tal modo que, neste campo de batalha, denominado vida, é preciso sempre sobressair-se, pois isto representa a felicidade, o bem estar e a alegria. Ao contrário, neste mesmo campo, não sobressair-se e, consequentemente, não 
atingir este objeto de busca, representa ser ultrapassado e, portanto, sofrer e ser infeliz. Mas ainda restaria outra alternativa, que não corresponderia a estar diante da possibilidade de ganhar e, em decorrência disto, ser feliz e, tampouco, correr o sério risco de não ultrapassar nesta corrida conflituosa e ser infeliz. Esta alternativa é ainda cogitada por Hobbes, mas é interpretada por ele como sinônimo de morte. Não participar deste conflito, afastar-se deste palco de lutas seria o mesmo que isolar-se da história, o que corresponde a morrer.

Ora, esta ideia de "conatus" sugere que um determinismo mecanicista está a reger toda a ação histórica do homem. Em princípio, poder-se-ia imaginar que este determinismo mecanicista estivesse regendo apenas o universo em sua totalidade. No entanto, quando Hobbes se propõe a analisar a ação humana e, consequentemente, a moral e a política, verifica-se que este pano de fundo se estende numa linha de coerência, também e, sobretudo, nesta área. Donde apenas ser possível compreender sua reflexão acerca da ação humana e, extensivamente, das ações moral e política, considerando este aspecto fundamental de seu pensamento.

Posto que o determinismo histórico mecanicista rege não apenas o universo, mas toda atividade psicológica do homem, Hobbes, numa linha de coerência e, nesta mesma ordem de ideias, aplica este elemento à questão política.

Sabemos que a política sempre ocupou grande parte dos objetos refletidos e trabalhados pelos pensadores desde a antiguidade grega até nossos dias. E a diferenciação em termos reflexivos nesta área é muito grande e chama-nos muito a atenção. Há, sem dúvida alguma, muitas ideias apresentadas e difundidas e que muito nos fazem pensar. Hobbes é um destes pensadores políticos que apresentou uma reflexão histórico-política por demais originária, cujas ideias podem se confrontar radicalmente com aquelas que creditam ao homem o grande mérito de possuir uma aptidão natural para viver de forma harmoniosa na sociedade. Confronta-se, especialmente, com aqueles que apostam na capacidade de o homem, uma vez educado, seja pelo estado ou pela família, mostrar-se habilitado a ter um comportamento civilizado dentro da realidade histórico-social, respeitando naturalmente as normas e, igualmente, de maneira natural, ser capaz de ser ético-moral, onde não apenas os seus interesses, mas os da coletividade sejam objeto de sua busca.

Em Hobbes, a temática política não é apresentada desta maneira. O homem não possui esta aptidão natural para uma vida em sociedade, integrando e construindo uma história civilizada e, tampouco, é possível a ele estar imbuído de boas e salutares intenções morais, éticas ou religiosas, constituindo-se, assim, um natural bom cidadão, desejoso do bem-estar não somente para si, mas para todos de uma forma geral. 
O termo lobo é utilizado por Hobbes para descrever a verdadeira situação do homem, inserido no estado por ele denominado de natural. Ao usar este termo, Hobbes desejou remontar e trazer à tona a ideia do perigo, da ameaça, da violência associada à outra ideia, a de exposição a que se encontram os demais. A ideia de ameaça é inerente à ideia de estado natural, no qual se encontrariam os homens. Há outro termo bastante utilizado por Hobbes para retratar a situação criada naturalmente pelos homens no estado natural, a saber, guerra. Vejamos:

É uma guerra que é de todos os homens contra todos os homens. Pois a guerra não consiste apenas na batalha, ou no ato de lutar, mas naquele lapso de tempo durante o qual a vontade de travar batalhas é suficientemente conhecida. Portanto a noção de tempo deve ser levada em conta quanto à natureza da guerra, do mesmo modo que quanto à natureza do clima. Porque tal como a natureza do mal tempo não consiste em dois ou três chuviscos, mas numa tendência para chover que dura vários dias seguidos, assim também a natureza da guerra não consiste na luta real, mas na conhecida disposição para tal, durante todo o tempo em que não há garantia do contrário. Todo o tempo restante é de paz (HOBBES, 1988, 75).

O estado natural apresenta, portanto, estas duas características, sendo que uma se encontra bem relacionada com a outra: o homem é interpretado como sendo o lobo para o outro homem e a situação interna deste estado como o de guerra de todos contra todos. Estes dois termos, portanto, traduzem, de forma sistemática, a situação histórica do homem mergulhado no estado natural que para Hobbes outra situação não é, senão o de selvageria.

Em termos concretos, para Hobbes, a utilidade histórica é a medida adotada no denominado estado natural. Significa que, em função de suas paixões naturais, os homens, de maneira geral, são levados a buscar aquilo que lhes proporciona o prazer e a satisfação. A conquista dos bens é uma necessidade imperiosa para todos, de tal modo que não estar ligado a esta busca, não pode ser considerado uma atitude natural, mas sim um desvio da conduta natural. Tudo aquilo que resulta no prazer, na comodidade é buscado em função desta utilidade natural.

Nesta situação onde, historicamente, se encontram os homens, estado natural, é impensável falar-se em altruísmo. Não existe sequer a possibilidade de se pensar neste sentimento, pois atitudes semelhantes a este gênero constituiriam anormalidade. $\mathrm{O}$ natural seria o egoísmo interpretado como busca de satisfação de interesses pessoais, não se importando com as demais pessoas. O que está em jogo é, única e exclusivamente, o desejo irrequieto de satisfazer a todo e qualquer custo os interesses pessoais, colocando completamente de lado qualquer preocupação com a coletividade e com os interesses da coletividade. Esta é, historicamente, a inclinação geral do gênero humano, conforme é descrito por Hobbes, marcado tão somente por um obcecado desejo de possuir cada vez mais, associado, naturalmente, ao de 
poder. Quanto maior o número de posses e o grau de poder, maior é a sua felicidade dentro da história.

Hobbes ainda fala de outro aspecto presente neste estado de natureza e que, à primeira vista, pode parecer-nos contraditório. Se, por um lado, aponta a necessidade de um despotismo político, adversário da democracia, por outro, sugere que todos os homens são naturalmente iguais. Mas em que se baseia esta igualdade? Há, no entendimento deste pensador, a ideia de que existe um direito universal, portanto, comum a todos os homens. E todos possuem o desejo da autopreservação que, em termos concretos, traduz-se pelo fato de que todos possuem o direito de procurar não apenas o necessário, mas também o cômodo à vida. Isto é o que vai fundamentar o que ele considera como sendo o direito fundamental da autopreservação. No entanto, deve ser considerada a existência histórica e o predomínio deste direito universal de autopreservação, dentro de uma situação marcada pela completa ausência de normas comuns de convivência. E assim torna-se possível imaginar a conturbada vida neste estado natural. A colocação deste filósofo, neste sentido, sugere-nos imaginar cada um, de forma desenfreada e destituída de qualquer critério e normas sociais, exercitando este direito universal. Eis as palavras de Thomas Hobbes:

O direito de natureza, a que os homens geralmente chamam Jus naturale, é a liberdade que cada homem possui de usar o seu próprio poder, de maneira que quiser para a preservação de sua própria natureza, ou seja, de sua vida: e consequentemente de fazer tudo aquilo que seu próprio julgamento e razão lhe indiquem como meios para esse fim (Hobbes, 1988, 78).

A partir do acima apresentado, não é difícil deduzir, a partir desta situação a inevitabilidade do conflito histórico, no qual cada um recorre aos meios de que dispõe para fazer valer cada vez mais o seu direito da autopreservação. Considerando que, mesmo em situação menos favorecida fisicamente, o indivíduo pode lançar mão de recursos disponíveis na natureza para fazer valer este seu direito natural. Visto que as aptidões intelectuais são iguais, podemos imaginar um ambiente, onde o recurso à violência generaliza-se completamente. Fica evidente a existência de um quadro histórico-social onde todos arquitetam elaborar meios, os mais eficazes possíveis para serem colocados a serviço da destruição do outro. E a consequência de todo este quadro de exposição, perigo e ameaça constantes é que a vida torna-se, não apenas frágil, mas especialmente solitária, pobre, sórdida e curta. Pode-se assim dizer, torna-se uma realidade histórico-social na qual o homem é lobo para o outro homem e o convívio humano não se torna outra coisa senão o que Hobbes descreve como sendo uma guerra de todos contra todos. 
Em decorrência de tudo isto que acontece em função deste exercício sem limites, dentro da história de busca desenfreada do que necessita e é cômodo à vida, o estado natural exige uma saída que, surpreendentemente deverá se embasar no próprio direito universal da autopreservação. A exigência, segundo Hobbes, parte da constatação, em um determinado instante, de não ser possível que a vida permaneça eternamente marcada pela solidão, pobreza e embrutecimento. $\mathrm{O}$ direito universal da autopreservação, portanto, vai pedir uma nova ordem diferente de todo este quadro histórico que caracteriza o estado natural. $\mathrm{O}$ instinto de conservação de que nos fala Hobbes é, deste modo, abertura para duas situações completamente distintas e verdadeiramente contraditórias do ponto de vista histórico, social e político. Quando este instinto é deixado a si, o mesmo torna-se um canal para a violência para o quadro histórico generalizado de destruição do próximo. Ao mesmo tempo, este mesmo instinto de preservação constitui-se em porta para a criação de uma paz tática que prometa a conservação, tendo como ponto de partida a percepção da inviabilidade da vida, marcadamente embrutecida e selvagem, na forma como esta acontece no estado natural.

Diferentemente da maior parte dos pensadores políticos, especialmente dos clássicos, Platão, em A Política e Aristóteles, em Ética à Nicômaco, para Hobbes, a inserção na sociedade não se dá de forma natural. Para aqueles, o homem possui naturalmente uma vocação para a vida em sociedade. Esta é como que uma condição natural para a sua vida histórica, social e política que requer a realização. Assim a vida histórico-social é uma necessidade e condição de realização, pois é nela que o cidadão desenvolve suas relações políticas e sociais. A única sugestão apresentada é, antes desta inserção e até mesmo como forma de aprimorar a civilidade, que o indivíduo receba uma educação, seja ela sob os cuidados da família ou do estado. Assim, o homem é definido como animal social e que está naturalmente inclinado a viver dentro de uma ordem na cidade.

Em Hobbes, a inserção não acontece de maneira natural e espontânea. O indivíduo não nasce vocacionado historicamente para a vida social. Ele não entra na sociedade por ser um animal social e, tampouco, por ser naturalmente inclinado a viver dentro de uma ordem estabelecida. A entrada do homem na sociedade acontece em função de uma necessidade premente. É condição para sair de uma vida de tal modo embrutecida, que se tornou completamente impossível viver. Esgotam-se, radicalmente, as possibilidades de viver com segurança e tranquilidade. Daí não há outra opção, senão entrar em um estado diferente do de então, como maneira de exorcizar o medo, a intranquilidade, o embrutecimento e a solidão. Somente depois desta experiência natural e desastrosa, do ponto de vista do convívio, é que o 
indivíduo vai desejar outra forma de vida social. E sobre este aspecto, a reflexão de Hobbes muito se aproxima de Rousseau em O Contrato social, Locke em Dois tratados do governo civil. Os indivíduos entram para a sociedade somente depois de constatarem que a preservação da vida está totalmente ameaçada.

A mudança histórica, saindo deste campo de batalha para uma situação de paz e de segurança histórico-social passa pela percepção de que é preciso fazer um acordo que, longe de ser natural, é marcadamente artificial. Mas ainda assim, este se faz imperioso e necessário, uma vez que a autopreservação se torna palavra de ordem. E a condição encontrada para assegurar esta preservação é a opção de todos pela paz, traduzida na realização do pacto social. Somente ele pode assegurar a paz que é a dimensão mais inerente e asseguradora de fato da desejada autopreservação. E deste modo que os homens, ensina Hobbes, são levados a estabelecer pactos entre si. É ainda, segundo ele, a única motivação que conduz ao estabelecimento de pactos, onde fica descartada a possibilidade da existência de sentimentos altruístas ou qualquer outra forma de motivação interna considerada nobre e edificante do ponto de vista ético e moral.

Mas em que consiste este contrato na visão de Hobbes? O pacto envolve partes onde se sela um acordo, partindo-se da pressuposição de que existem chances de cumprimento do que foi acordado. Antes de mais nada, ele exige que haja, de fato, a possibilidade da parte dos que vão abrir mão da liberdade absoluta em cumprir o que é selado como acordo. Por isto mesmo, ele envolve uma promessa, a saber, a promessa de cumprimento. E esta é a condição fundamental para que ele vigore, pois em situação contrária, ou seja, não havendo o cumprimento do pacto, o mesmo perde a sua validade. Ele é também o responsável pela criação da ordem moral e da civil. E assim, como o pacto social é imprescindível no processo de estabelecimento da paz e da concórdia através da expulsão do embrutecimento presente no meio do grupo, também o será na perpetuação desta paz social.

Com a nova ordem e o estabelecimento do estado de direito, será importante que as relações entre as pessoas sigam um curso diferente daquele típico do estado natural. Enquanto lá, as preocupações voltavam-se exclusivamente para os interesses pessoais, sem se importar com o outro, a nova sociedade, possuidora da ordem moral e civil, exigirá do indivíduo uma postura típica de civilizado. A preocupação meramente individualista cede espaço para preocupação com o coletivo, com o social, visto que as normas de convivência, mesmo as mais elementares, estarão considerando o grupo como um todo. Não serão normas que visem apenas os interesses pessoais. E ainda que estas possam ser atualizadas, por não serem absolutas e transcendentais, estarão sempre sujeitas à ética. E em função do que é exposto, o indivíduo é 
sempre convidado, pelas normas de convivência, a nunca fazer aos outros o que não gostaria que os outros fizessem a si. Importa dizer que, ainda que artificialmente, o indivíduo é, pela força da lei decorrente do contrato social estabelecido, instado a pensar no outro e a ver-se sempre numa relação com os demais, onde os seus interesses precisam ser conjugados com os dos demais cidadãos.

Mas não se pode perder de vista o que Hobbes considera como sendo o natural, que é o homem gozando desta liberdade absoluta, sem que tenha outra preocupação senão o de zelar pelo seu direito natural, que é o de sua autopreservação. E, por este motivo, lançar mão de todos os recursos disponíveis para conseguir os bens necessários à sua sobrevivência e à sua comodidade. Do mesmo modo, é preciso considerar que o estado de direito, longe de ser o natural, é o estado artificial, criado, a partir do próprio direito universal de autopreservação. E que a motivação para o seu desejo distancia de qualquer sentimento nobre e ético, mas que possui como motivação interesses exclusivamente egoístas, o de preservar-se e espantar um estilo de vida pobre, ameaçador e embrutecido. A guerra de todos contra todos não poderia ser mais admitida, bem como a percepção de que o homem é lobo para o outro homem sempre prestes a ataca-lo.

E, por ser este um estado artificial e não natural, qual é a garantia para que o pacto social seja respeitado e que as normas de convivência social sejam sempre levadas em consideração? Qual é a garantia de que o homem não voltará a agir como antes, voltando a se preocupar apenas consigo, com sua autopreservação, com sua subsistência e sua comodidade?

Hobbes, em função do que considera natural e artificial, sugere que o pacto em si é por demais precário. É como se o nosso pensador visse o homem sempre prestes a ter uma recaída e a retornar ao seu estado natural, visto que, ao contrário da maioria dos pensadores políticos, o homem não é visto como possuidor de uma inclinação natural para a vida em sociedade. Por isto, Hobbes assegura que este pacto selado não é suficientemente forte para fornecer todas as garantias de uma paz definitiva e tranquilizadora ao corpo social. O pensador vê a possibilidade de surgirem pessoas no meio social, imbuídas de interesses tipicamente naturais, a desejar trazer o poder apenas para si, com a preocupação somente em fortalecer-se egoisticamente.

Diante de tal constatação e perigo, Hobbes sugere a necessidade de submeter a vontade individual à vontade de um único homem ou a uma assembleia determinada. O escolhido receberia a delegação de zelar pela paz e, neste seu empreendimento contar com o respaldo de todos os membros do corpo social. Seria necessariamente acompanhado por todas as pessoas 
em decisões onde estivesse em jogo o exercício da tarefa que lhe foi delegada, conforme podemos verificar:

Diz que um estado foi instituído quando uma multidão de homens concordam e pactuam, cada um com cada um dos outros, que a qualquer homem ou assembleia de homens a quem seja atribuído pela maioria o direito de representar a pessoa que todos eles (ou seja, de ser seu representante), todos em exceção, tanto os que votaram a favor dele como os que votaram contra ele, deverão autorizar todos os seu atos e decisões desse homem ou assembleia de homens, tal como se fossem seus próprios atos e decisões, a fim de viverem em paz uns com os outros e serem protegidos dos restantes dos homens (HOBBES, 1988, 107).

E, mais que isto, Hobbes afirma que, como forma imprescindível de se ter esta situação assegurada, na história social e política e não correr riscos de rompimento do contrato social, este poder que foi delegado possui somente uma forma de ser exercido, a saber, mediante o absolutismo. É aqui que se encontra a originalidade e novidade do pensamento político de Hobbes. Por um lado, é favorável a um pacto que é sinônimo de acordo, respaldado pela liberdade individual dos homens que desejam uma situação nova. Por outro lado, admite a necessidade do absolutismo político como forma única de o estado soberano exercer o poder com vistas a ver assegurado definitivamente a paz social.

O que pode ser tomado à primeira vista como sendo uma contradição interna de seu pensamento não o é. Especialmente, quando atentamente se observa que o estado soberano e absoluto é uma decorrência necessária do pacto social. E que, sem esta forma de exercer o poder, considerando a inclinação natural do homem que não é a de um ingresso natural na realidade histórico-social, o precário acordo pode ser quebrado a qualquer momento, acarretando as consequências, dentre as quais, o retorno do estado de selvageria.

Há, portanto, no pensamento político de Hobbes um equacionamento nesta área e que não é outra coisa, senão a derivação de como este pensador encara o pacto social. Isto acontece com a participação somente dos membros do grupo natural, desejosos de outra ordem diferente daquela experimentada e que abrem mão do direito natural a tudo, criando uma instituição soberana à qual será delegado o poder de assegurar o estado de direito. Por sua vez, a instituição criada, uma vez de posse desta delegação, deverá tão somente se preocupar em exercer bem a sua função política. Deriva-se disto a afirmação de Hobbes de que o soberano dará satisfações somente a Deus. E este, por não estar submetido a nada, a nenhum outro poder: "É desta instituição do Estado que derivam todos os direitos e faculdades daqueles a quem o poder soberano é conferido mediante o consentimento do povo reunido" (HOBBES, 1988, 106).

Por ser absoluto, ter a obrigação de prestar contas de sua gestão política somente a Deus, e, especialmente, por ser a própria fonte legisladora, as pessoas lhe devem total e completa 
obediência. Um aspecto merecedor de atenção e ressaltado por Hobbes é que, por se tratar de delegação, há uma função a ser integral e rigorosamente exercida como parte de todo este acordo. Subjacente a isto, encontra-se a ideia de correspondência por parte do soberano. Ele é a personificação de um estado inteiramente absoluto e é de extrema importância. Este deve cumprir o que constitui o desejo político de todos que agora fazem parte da nova ordem. A obediência a ele é sem reservas, pois goza de poderes ilimitados e do mesmo se espera a potência política capaz de assegurar o estado de direito, a paz durável e a prosperidade.

Tudo aquilo que possa representar ameaça ao poder civil e comprometer a paz estabelecida deve ser objeto da gestão do soberano. Neste aspecto inclui até mesmo a religião, a qual pode, eventualmente, ser objeto de conflitos e desavenças. Por isto mesmo Hobbes sugere a inclusão do poder religioso no âmbito do soberano.

Consideramos, finalmente, que esta tradição contratualista que possui sua melhor expressão no pensamento político de Hobbes, pode, ocasionalmente, servir como fonte de inspiração para os regimes absolutistas e que utilizarão de argumentos e modelos inspirados nesta corrente para se instalarem como poderes políticos.

\section{REFERÊNCIAS BIBLIOGRÁFICAS}

ARISTOTE. Étique à Nicomaque. Paris: G F Flammarion, 2004.

HOBBES, T. Leviatã, ou matéria e forma de um estado eclesiástico e civil. Tradução: Paulo Monteiro e Maria Beatriz Nizza da Silva. 4. ed. São Paulo: Nova Cultural, 1988. (Os Pensadores).

LOCKE, J. Dois tratados do governo civil. São Paulo: Martins Fontes, 2001.

PLATON. Oeuvres Complètes. Tome VI, La République. Paris: Societé D’édition Les Belles Lettres, 1947.

ROUSSEAU, J.J. Oeuvres complètes. Direction de Bernard Gagnebin et Marcel Raymond. Paris: Gallimard, 1964. (Bibliothèque de la Pléiade). 